\title{
Antipsychotic patterns of use in patients with schizophrenia: polypharmacy versus monotherapy
}

\author{
Maxine D Fisher ${ }^{1}$, Kathleen Reilly ${ }^{1}$, Keith Isenberg ${ }^{2}$ and Kathleen F Villa ${ }^{3^{*}}$
}

\begin{abstract}
Background: The objective of this study was to characterize real-world treatment patterns in the prescription of antipsychotic polypharmacy ( $\geq 2$ concurrent antipsychotics) compared with antipsychotic monotherapy for patients with schizophrenia.

Methods: This study was a retrospective claims-based analysis of patients (aged 13-64 years) with schizophrenia belonging to an employer-based health plan. Duration of therapy was measured as the number of treatment days over one year following the initial date of antipsychotic therapy. Discontinuation was defined as a 90-day gap in antipsychotic treatment (or in at least one antipsychotic for the polypharmacy group). Logistic regression analyses were used to predict discontinuation within one year. Ordinary Least Squares (OLS) regressions were used to predict duration of therapy (by type of therapy) when controlling for gender, region, number of somatic and psychiatric comorbidities, Deyo-Charlson comorbidity score, and number of psychiatric and somatic medications.

Results: Of the 4,156 patients, 3,188 received monotherapy and 968 received polypharmacy. Mean age was 40 years (37.8 years for polypharmacy vs 40.3 years for monotherapy, $\mathrm{p}<0.001$ ). Within one year, $77 \%$ of the polypharmacy group and $54 \%$ of the monotherapy group discontinued treatment. The average duration of therapy was 163 [SD =143] days in the polypharmacy group vs 253 [SD =147] days in the monotherapy group. In both cohorts, patients $<25$ years had a higher frequency of discontinuations than those $\geq 26$ years. Age and polypharmacy were independent predictors of treatment duration and discontinuation prior to one year.
\end{abstract}

Conclusions: One quarter of patients with schizophrenia received antipsychotic polypharmacy. Discontinuation was higher in the polypharmacy group. Age and polypharmacy were significant predictors of treatment discontinuation.

Keywords: Schizophrenia, Polypharmacy, Claims-based analysis, Patterns of use

\section{Background}

Antipsychotics have limited impact on the negative symptoms of schizophrenia and are not consistently or fully effective against positive symptoms $[1,2]$. This can lead to poor patient outcomes, including relapse and hospitalization [3,4]. Even with adequate antipsychotic treatment, many patients with schizophrenia continue to experience symptoms: according to the W-SOHO study, 15-39\% experience a persistent symptomatic course and $14-21 \%$ of those experiencing remission subsequently relapse within a three-year period [5]. Current clinical practice commonly involves combining antipsychotics to improve treatment of patients with suboptimally controlled

\footnotetext{
* Correspondence: kathleen.villa@jazzpharma.com

${ }^{3}$ Jazz Pharmaceuticals, Inc., 3180 Porter Drive, Palo Alto, CA 94304, USA

Full list of author information is available at the end of the article
}

symptoms of schizophrenia, despite the lack of robust evidence for this approach, the increased risk of side effects, and the cost implications [6-9]. Polypharmacy prevalence rates vary widely from $2-70 \%$ [10-21] depending on study design, patient population, diagnosis, and geographical region, with a median of $19.6 \%$ of patients worldwide receiving multiple antipsychotics [22]. Polypharmacy prevalence is expected to continue to rise as more antipsychotics become available and as physicians become more familiar with the practice $[11,22,23]$.

Evidence supporting polypharmacy is lacking, however. The majority of published studies regarding the use of two or more antipsychotics are limited to combinations with clozapine - which held the promise of improving effectiveness by taking advantage of medications with different mechanisms of action and side-effect 
profiles [6,8,10,24-27] - and have not demonstrated superior efficacy of polypharmacy [10,24,27-29]. Initially, it was believed that combining antipsychotics at lower doses could improve effectiveness without increasing the risk of treatment-related side effects associated with escalating doses of single agents [10]. However, polypharmacy has been associated with excessive total antipsychotic doses, which may increase dose-related side effects, the risk for drug interactions, and complicated dosing regimens that may lead to treatment discontinuation [10,16,28,29]. In the absence of clear benefit, treatment guidelines largely discourage the use of antipsychotic polypharmacy for the treatment of schizophrenia [30]. Polypharmacy is recommended for limited situations in which the patient has failed at least three trials of antipsychotic monotherapy of adequate dose and duration, including clozapine [29].

Along with the paucity of research regarding the efficacy of polypharmacy, little is known about the characteristics of patients who receive polypharmacy versus monotherapy for the treatment of schizophrenia. To fill these gaps in current knowledge, this study characterized real-world treatment patterns, including medication switching and discontinuation, in patients with schizophrenia treated with antipsychotic monotherapy versus those treated with polypharmacy.

\section{Methods}

This retrospective cohort analysis included patients selected from the HealthCore Integrated Research Environment (HIRE), a database of medical, laboratory, and pharmacy claims of commercially insured patients. The HIRE contains administrative claims data from 14 major commercial health plans across the United States, representing 45 million lives.

As a non-interventional, observational analysis, no patients were directly involved in the study. The study was conducted in compliance with state and federal laws, including the Health Insurance Portability and Accountability Act (HIPAA) of 1996.

A chart review was included in this study and approval for a complete waiver of HIPAA authorization was granted by a central Institutional Review Board (Quorum Review IRB, waiver \#26699) prior to chart collection. All claims were from a limited dataset with anonymized patient information.

\section{Patients}

Patients between the ages of 13 and 64 years who had two or more claims for schizophrenia (International Classification of Diseases, 9th edition code 295.xx) from January 1, 2007 through to April 30, 2010 were included in the study. The younger patients were included in order to be able to describe the treatment patterns not only for chronic schizophrenia patients, but also for those who are at the earliest stages of their diagnosis and disease. Patients were followed for one year subsequent to the first claim for schizophrenia (the index date).

Antipsychotic medications were identified from pharmacy claims closest to the index date ( \pm 90 days). All first-generation (FGA) and second-generation (SGA) antipsychotics were included. Patients with a prescription for an FGA and/or SGA within 90 days before or after the index date were stratified by type of therapy into the monotherapy or polypharmacy cohorts. The first of these prescriptions was defined as the index medication. Monotherapy was defined as a single antipsychotic medication, whereas polypharmacy was defined as having two or more antipsychotics within a 45-day period. Short-acting antipsychotics given by injection for acute treatment were excluded to eliminate the possibility of mis-categorizing patients taking medications in an inpatient setting. Long-acting injections were not included because we found their use to be low in the claims $(<2 \%$ overall, data not shown).

From the list of all schizophrenia patients included in the study, a random sample of 200 was targeted for medical record review. Patients were required to have documented schizophrenia in their medical record.

\section{Outcome measures}

Because clinical outcome measures are not available in administrative claims data, the primary outcome measure used in this analysis was duration of therapy, measured over one year following the date antipsychotic treatment was initiated. Treatment duration was defined as the number of days without a 90-day gap in treatment. Discontinuation was defined as a 90-day gap in antipsychotic therapy prior to the end of the one year follow-up period. In the polypharmacy group, discontinuation was defined as a 90-day gap in at least one of the antipsychotic medications during follow-up.

Secondary outcomes included the type and number of psychiatric and somatic comorbidities during the one year follow-up period. Psychiatric comorbidities included depression, anxiety, bipolar, schizoaffective, attentiondeficit and personality disorders. Analysis of somatic comorbidities included the Deyo-Charlson Comorbidity Index (DCI) score [31] and the proportion of patients with claims for cardiovascular diseases, cerebrovascular disease, diabetes, hyperglycemia, or hyperlipidemia. Concomitant psychiatric medications other than antipsychotics, including antidepressants, anxiolytics, hypnotics and sedatives, mood stabilizers, and stimulants, were recorded. The type and number of somatic medications, including lipid-modifying agents, anti-diabetic agents, anti-Parkinson disease and movement disorder medications, cardiovascular agents, and anti-obesity drugs were also collected. 
A random sample of 200 patients within the larger claims cohort was selected for medical chart review to estimate schizophrenia severity because this is not available in claims data. Severity within the sub-sample was determined from physician documentation in the charts and described as mild, moderate or severe. Due to the small number of patients with documented schizophrenia severity, comparisons between polypharmacy and monotherapy groups were descriptive only.

\section{Statistical analysis}

Measures were described as means ( \pm standard deviation [SD]) for continuous variables, and frequencies for categorical variables. Differences in mean length of therapy were compared using $t$ tests, and $\chi^{2}$ tests were used to compare the proportion of patients discontinuing treatment and the prevalence of comorbidities. Ordinary Least Squares (OLS) regression was used to predict the length of therapy (by type of antipsychotic therapy regimen), when controlling for gender, region, number of somatic and psychiatric comorbidities, DCI score, and the number of psychiatric and somatic medications.

\section{Results}

\section{Patient characteristics}

A total of 4,156 patients were included in the study. Of these, 3,188 were in the monotherapy cohort and 968 were in the polypharmacy cohort (Table 1 ). Overall, $53.1 \%$ were

Table 1 Patient characteristics at baseline (6 months pre-index)

\begin{tabular}{|c|c|c|c|c|}
\hline Characteristic & $\begin{array}{l}\text { Total } \\
(\mathrm{N}=4,156)\end{array}$ & $\begin{array}{l}\text { Monotherapy } \\
(\mathrm{n}=3,188)\end{array}$ & $\begin{array}{l}\text { Polypharmacy } \\
(\mathrm{n}=968)\end{array}$ & p-value ${ }^{a}$ \\
\hline Length of follow-up, days (mean, SD) & $993.5(391.8)$ & $989.3(393.8)$ & $999.3(397.1)$ & .488 \\
\hline \multicolumn{5}{|l|}{ Gender, n (\%) } \\
\hline Male & $2206(53.1)$ & $1,710(53.6)$ & $496(51.2)$ & .190 \\
\hline Age at index date, years (mean, SD) & $40(13.7)$ & $40.3(13.6)$ & $37.8(13.6)$ & $<.001$ \\
\hline \multicolumn{5}{|l|}{ Psychiatric comorbidities, n (\%) } \\
\hline Depression & $1090(26.2)$ & $806(25.3)$ & $284(29.3)$ & .012 \\
\hline Schizoaffective disorders & $991(23.8)$ & $786(24.7)$ & $205(21.2)$ & .026 \\
\hline Anxiety disorders & $441(10.6)$ & $336(10.5)$ & $105(10.8)$ & .786 \\
\hline Bipolar disorder & $247(5.9)$ & $190(6.0)$ & $57(5.9)$ & .934 \\
\hline Personality disorders & $128(3.1)$ & $94(2.9)$ & $34(3.5)$ & .374 \\
\hline Attention deficit disorder & $114(2.7)$ & $83(2.6)$ & $31(3.2)$ & .318 \\
\hline Substance use disorder & $83(2.0)$ & $59(1.9)$ & $24(2.5)$ & .221 \\
\hline \multicolumn{5}{|l|}{ Psychiatric medications, n (\%) } \\
\hline Antidepressants & $2016(48.5)$ & $1516(47.6)$ & $500(51.7)$ & .025 \\
\hline Sedatives or hypnotics & $1623(39.1)$ & $1051(33.0)$ & $572(40.9)$ & $<.001$ \\
\hline Mood stabilizers & $1073(25.8)$ & $794(24.9)$ & $279(28.8)$ & .015 \\
\hline Anti-anxiety medications & $926(22.3)$ & $678(21.3)$ & $248(25.6)$ & .004 \\
\hline Stimulants and ADHD medications & $40(1.0)$ & $32(1.0)$ & $8(0.8)$ & .621 \\
\hline Mean (SD) Deyo-Charlson Comorbidity Index Score (range 0-16) & $0.6(1.0)$ & $0.6(1.0)$ & $0.6(0.9)$ & .546 \\
\hline \multicolumn{5}{|l|}{ Somatic medications, n (\%) } \\
\hline Anti-hyperlipidemic agents & $623(15.0)$ & $490(15.4)$ & $133(13.7)$ & .213 \\
\hline Anti-hypertensive agents & $502(12.1)$ & $408(12.8)$ & $94(9.7)$ & .010 \\
\hline Anti-thyroid agents & $418(10.1)$ & $310(9.7)$ & $108(11.2)$ & .194 \\
\hline Anti-diabetic agents & $358(8.6)$ & $275(8.6)$ & $83(8.6)$ & .960 \\
\hline Anti-Parkinson agents & $60(1.4)$ & $37(1.2)$ & $23(2.4)$ & .005 \\
\hline \multicolumn{5}{|l|}{$\begin{array}{l}\text { Random sample of patients with baseline disease severity data } \\
\text { available from charts }(n=121), n(\%)\end{array}$} \\
\hline Mild & $25(20.7)$ & $22(23.2)$ & $3(11.5)$ & \\
\hline Moderate & $31(25.6)$ & $25(26.3)$ & $6(23.1)$ & \\
\hline Severe & $65(53.7)$ & $48(50.5)$ & $17(65.5)$ & \\
\hline
\end{tabular}

$\mathrm{ADHD}=$ attention deficit hyperactivity disorder; $\mathrm{SD}=$ standard deviation. aPolypharmacy vs monotherapy. 
male $(53.6 \%$ in the monotherapy group and $51.2 \%$ in the polypharmacy group).The mean age was 40 years, with patients in the polypharmacy group significantly younger than those in the monotherapy group (37.8 vs. 40.3 years, respectively, $\mathrm{p}<0.001$ ).

At baseline, $26.2 \%$ of the overall patient population had comorbid depression $(29.3 \%$ and $25.3 \%$ in the polypharmacy and monotherapy cohorts, respectively; $\mathrm{p}=$ 0.012 ) and $23.8 \%$ had comorbid schizoaffective disorders $(21.2 \%$ and $24.7 \%$, respectively; $\mathrm{p}=0.026)$. There was no statistical difference in the DCI score between the two groups at baseline. Patients in the polypharmacy group had significantly higher use of concomitant psychiatric medications (other than antipsychotics) at baseline compared with the monotherapy group, notably antidepressants (51.7 vs. $47.6 \%)$, sedatives (40.9 vs. $33.0 \%)$, mood stabilizers excluding antipsychotics $[27,32,33]$ (28.8 vs. $24.9 \%$ ), and anxiolytics (25.6 vs. $21.3 \%$ ). The monotherapy group had a statistically higher proportion of patients with claims for anti-hypertensive agents compared with the polypharmacy group (12.8 vs. 9.7\%; $\mathrm{p}=0.010)$. Claims for anti-Parkinson agents were higher in the polypharmacy group compared to the monotherapy group (2.4 vs. $1.2 \% ; \mathrm{p}=0.005$ ) (Table 1 ).

In the sample of 200 patient charts selected for assessment of schizophrenia severity, 188 patients were receiving antipsychotic medications. Of these 188 patients, 121 patients had a severity rating within 30 days of the index date. Among those, a higher proportion of patients in the polypharmacy cohort were rated as having severe disease compared with those in the monotherapy cohort (65.5 vs. $50.5 \%$ ), whereas, more patients in the monotherapy group were rated as having mild disease than those in the polypharmacy group (23.2 vs. 11.5\%) (Table 1).

\section{Index antipsychotic use}

Table 2 outlines the specific antipsychotics and antipsychotic combinations that were used in the two groups. For the $76.7 \%$ of patients who were on monotherapy, the most frequently used antipsychotic was risperidone (24\%). Among the $23.3 \%$ of patients in the polypharmacy cohort, $63.2 \%$ of the combinations included olanzapine, risperidone, or another SGA other than clozapine. The most commonly used combination was quetiapine plus risperidone (9.9\%). Only $10.2 \%$ of the polypharmacy combinations included clozapine. Slightly more than a quarter of the polypharmacy combinations (26.5\%) included an FGA. In comparison, only $13.4 \%$ of those in the monotherapy cohort received an FGA as index therapy.

\section{Discontinuation and duration of therapy}

A higher proportion of patients in the polypharmacy cohort discontinued index treatment prior to the end of
Table 2 Index antipsychotic therapies

\begin{tabular}{ll}
\hline Therapy & $\begin{array}{l}\text { Total N }=\mathbf{4 , 1 5 6} \\
\mathbf{n}(\%)\end{array}$ \\
\hline Patients on monotherapy (\% of total) & $3,188(76.7)$ \\
$\begin{array}{l}\text { Number of patients by type of antipsychotic } \\
\text { monotherapy (\% of monotherapy) }\end{array}$ & \\
Risperidone & $765(24.0)$ \\
Aripiprazole & $536(16.8)$ \\
Olanzapine & $505(15.8)$ \\
Quetiapine & $437(13.7)$ \\
Ziprasidone & $261(8.2)$ \\
Clozapine & $200(6.3)$ \\
Other second-generation antipsychotic & $57(1.8)$ \\
First-generation antipsychotic & $427(13.4)$ \\
Total on polypharmacy (\% of total) & $968(23.3)$ \\
Number of patients by type of antipsychotic & \\
polypharmacy combinations (\% of polypharmacy) & \\
Combinations with first-generation antipsychotics & $257(26.5)$ \\
Combinations with olanzapine & $216(22.3)$ \\
Combinations with risperidone & $210(21.7)$ \\
Combinations with other second-generation & $186(19.2)$ \\
antipsychotics & $99(10.2)$ \\
Combinations with clozapine & \\
Top 5 polypharmacy combinations & $96(9.9)$ \\
Quetiapine and risperidone & $94(9.7)$ \\
Quetiapine and aripiprazole & $65(6.7)$ \\
Quetiapine and first-generation antipsychotic & \\
Aripiprazole and risperidone & \\
Aripiprazole and olanzapine & \\
\hline & \\
\hline
\end{tabular}

the one year follow-up period compared with the monotherapy group (Figure 1). Overall, $77 \%$ of those in the polypharmacy group discontinued at least one of their index antipsychotics within one year, whereas $54 \%$ of those in the monotherapy group discontinued their index medication within one year. A greater proportion of patients in the polypharmacy group discontinued therapy compared with those receiving monotherapy when all age groups were considered. In both the monotherapy and polypharmacy cohorts, patients younger than 25 years had a higher frequency of treatment discontinuation prior to one year than those 26 years and older (Figure 1).

The average duration of therapy (i.e., without a gap of 90 days or more) was significantly greater for patients in the monotherapy cohort than those in the polypharmacy cohort (252.7 [SD = 147.4] vs 163.8 [SD = 143.4] days; $\mathrm{p}<0.01$; Data not shown).

Among the patients included in the chart review sample, those with greater disease severity had a higher frequency of treatment discontinuation within one year compared 


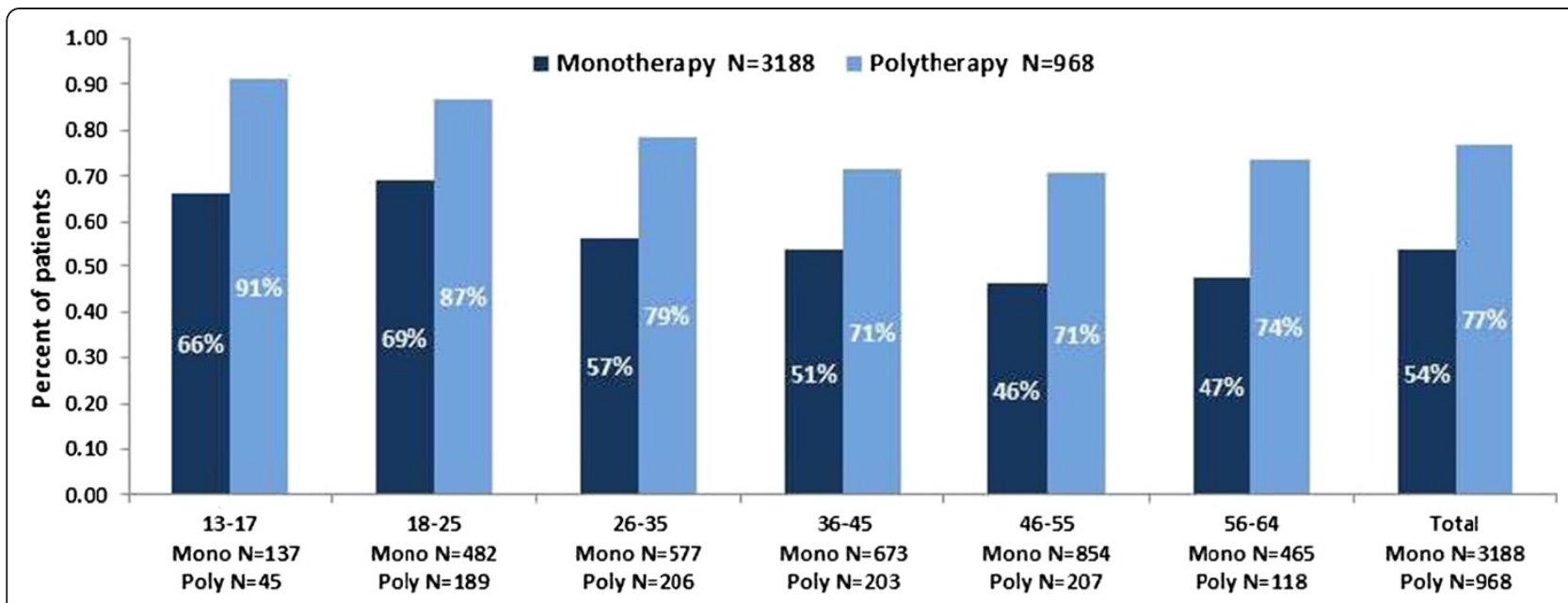

Figure 1 Percentage of patients, by age, who discontinued ${ }^{\mathrm{a}}$ within one year follow-up. ${ }^{\mathrm{a}}$ For polypharmacy patients, discontinuation was defined as a 90-day treatment gap in at least 1 index antipsychotic.

with patients who had mild or moderately severe disease (68 vs. $46 \%$; Data not shown).

In multiple regression analyses, both age and use of polypharmacy were independent predictors of length of therapy defined as the number of days on the index medication (Table 3). Additionally, receiving two or more psychiatric medications (that were not antipsychotics) was also independently associated with a shorter duration of antipsychotic therapy $(-13$ days; $\mathrm{p}<0.047)$.

After discontinuing antipsychotic therapy, $10.3 \%$ of patients in the monotherapy cohort restarted their index medication during the follow-up period, while $13.8 \%$ switched to a different antipsychotic (Table 4). Commensurate with its use as a treatment reserved for patients who have failed to respond to other antipsychotics, clozapine had the lowest proportion of patients (4.5\%) switching medications. Among the more commonly used antipsychotics, the patients who switched least often were those taking aripiprazole (8.8\%) (Table 5). In addition, aripiprazole was the most common second medication among patients in the monotherapy cohort who switched treatment (Figure 2). Patients receiving an SGA as index therapy but later switched tended to receive a different SGA as secondline therapy. Among patients who received an FGA as the

Table 3 Ordinary least squares (OLS) regression predicting length of therapy

\begin{tabular}{|c|c|c|c|}
\hline & & 95\% Confidence interval & \\
\hline Covariate $^{a}$ & Coef. & (lower - upper) & p-Value \\
\hline Polypharmacy (reference $=$ monotherapy) & -106.638 & $(-117.179--96.096)$ & $<.001$ \\
\hline Female (reference $=$ male) & -1.700 & $(-10.914-7.514)$ & .718 \\
\hline Age & 1.582 & $(1.198-1.965)$ & $<.001$ \\
\hline \multicolumn{4}{|c|}{ Number of post-index psychiatric comorbidities of interest (reference $=0$ ) } \\
\hline One & -9.402 & $(-19.946-1.142)$ & .081 \\
\hline Two & -38.278 & $(-52.526--24.031)$ & $<.001$ \\
\hline Three or more & -67.391 & $(-87.620--47.163)$ & $<.001$ \\
\hline \multicolumn{4}{|c|}{ Number of psychiatric medications post-index (reference $=0$ ) } \\
\hline One & -4.376 & $(-17.546-8.794)$ & .515 \\
\hline Two or more & -12.682 & $(-25.211--0.153)$ & .047 \\
\hline \multicolumn{4}{|c|}{ Number of somatic medications post-index (reference $=0$ ) } \\
\hline One & 20.108 & $(8.237-31.980)$ & .001 \\
\hline Two or more & 13.279 & $(-1.724-28.283)$ & .083 \\
\hline Constant & 218.211 & $(197.930-238.492)$ & $<.001$ \\
\hline$R^{2}$ & 0.148 & & \\
\hline
\end{tabular}

${ }^{a}$ Covariates not shown include plan region, number of somatic comorbidities, and Deyo-Charlson comorbidity index score. 
Table 4 Antipsychotic medication status after discontinuation among patients on monotherapy who discontinued (90-day gap in therapy) during one year follow-up

\begin{tabular}{ll}
\hline & $\begin{array}{l}\text { Total } \\
(\mathbf{n}=\mathbf{3 , 1 8 8})\end{array}$ \\
\hline Patients who discontinued prior to 12 months, $\mathrm{n}(\%)$ & $1706(53.5)$ \\
$\begin{array}{l}\text { Patients who restarted medication after } 90 \text { day gap in } \\
\text { treatment, } \mathrm{n}(\%)\end{array}$ & $317(10.3)$ \\
Mean time to restart, days (SD) & $182.7(59.3)$ \\
Patients who switched medications, $\mathrm{n}(\%)$ & $439(13.8)$ \\
Average time to first switch, days (mean, SD) & $166.9(100.7)$ \\
Number of switches, $\mathrm{n}(\%)$ & \\
$\quad$ One & $356(81.1)$ \\
Two & $58(13.2)$ \\
Three or more & $25(5.7)$ \\
\hline
\end{tabular}

index antipsychotic and later switched, half (50\%) switched to another FGA.

Among patients in the polypharmacy cohort who discontinued at least one of their index antipsychotics, $39.1 \%$ switched to monotherapy. Of those who switched to monotherapy, $21.1 \%$ remained on one of their index antipsychotics while $18.0 \%$ switched to a different agent (Table 6). Of the $17.2 \%$ of patients who remained on a polypharmacy regimen, $8.9 \%$ received a combination that included one of their index medications; $8.3 \%$ were switched to a polypharmacy regimen that included different medications. A substantial proportion of patients in the polypharmacy group who discontinued index therapy did not receive antipsychotics $(43.8 \%)$ for the remainder of the follow-up period.

\section{Discussion}

In this real-world cohort analysis, $23 \%$ of patients with schizophrenia were prescribed two or more antipsychotic medications. Although prevalence rates in previous studies

Table 5 Overall rate of switch during one year follow-up by index monotherapy

\begin{tabular}{ll}
\hline Index therapy & $\begin{array}{l}\text { Patients switching from } \\
\text { index therapy } \mathbf{n}(\%)\end{array}$ \\
\hline Aripiprazole & $47(8.8)$ \\
Clozapine & $9(4.5)$ \\
Olanzapine & $77(15.2)$ \\
Quetiapine & $67(15.3)$ \\
Risperidone & $119(15.6)$ \\
Ziprasidone & $41(15.7)$ \\
Other second-generation antipsychotic & $11(19.3)$ \\
First-generation antipsychotic & $68(15.9)$ \\
Total & $\mathbf{4 3 9 ( 1 3 . 8 )}$ \\
\hline
\end{tabular}

ranged from $2 \%$ to $70 \%$ [10-21], our findings are consistent with a worldwide median of $19.6 \%$ [21,22]. It is expected that the rates reported in our claims analysis would be lower than those reported elsewhere given that the database consisted of patients with schizophrenia who were members of employer-based health plans. Such patients would be expected to have lower schizophrenia severity as they would be required to maintain either steady employment or family relationships to retain health plan eligibility.

We found the highest polypharmacy rates among patients with more severe schizophrenia. Similarly, medical chart review suggested that more severe schizophrenia was seen in patients receiving polypharmacy. Among the youngest patients, whose early course may signal greater schizophrenia severity, polypharmacy rates were higher than those seen in older patients. It is possible that some patients using short-term polypharmacy were mis-classified in our study as receiving polypharmacy, causing slightly higher percentages than those in other studies. None of the patients categorized as polypharmacy had fewer than two concomitant fills. Injectable medications were excluded.

While approximately a quarter of patients receiving polypharmacy were prescribed a combination that included an FGA, the most frequently used combinations across all classes were combinations of SGAs. An additional examination of the treatment patterns by age showed that combinations of two FGAs were more frequent among patients in the two oldest age groups, whereas combinations with SGAs were more common in the younger age groups. Furthermore, our data show that patients who were transitioned off monotherapy were more often prescribed a second antipsychotic to the one that they had failed, rather than started on two new medications. Thus, within the older age groups, treatment patterns were consistent with guidelines that recommend polypharmacy only after the patient has failed trials of at least one additional SGA, an FGA, and finally clozapine. However, in our study population, the use of clozapine either alone or in combination was low.

Treatment patterns may have differed among age groups based on timing and availability of newer antipsychotics. Still, these data suggest that many physicians did not wait for patients in younger age groups to fail multiple types of treatments before moving to an antipsychotic polypharmacy regimen. This finding is consistent with previous research showing that physicians tend to prescribe multiple antipsychotics before exploring the full dose range of several different single antipsychotic agents $[10,19,33]$. Although it is understandable that physicians want to control severe acute symptoms of schizophrenia, particularly early in the course of disease, long-term use of polypharmacy beginning at an early age may pose additional risk to patients and warrants further 


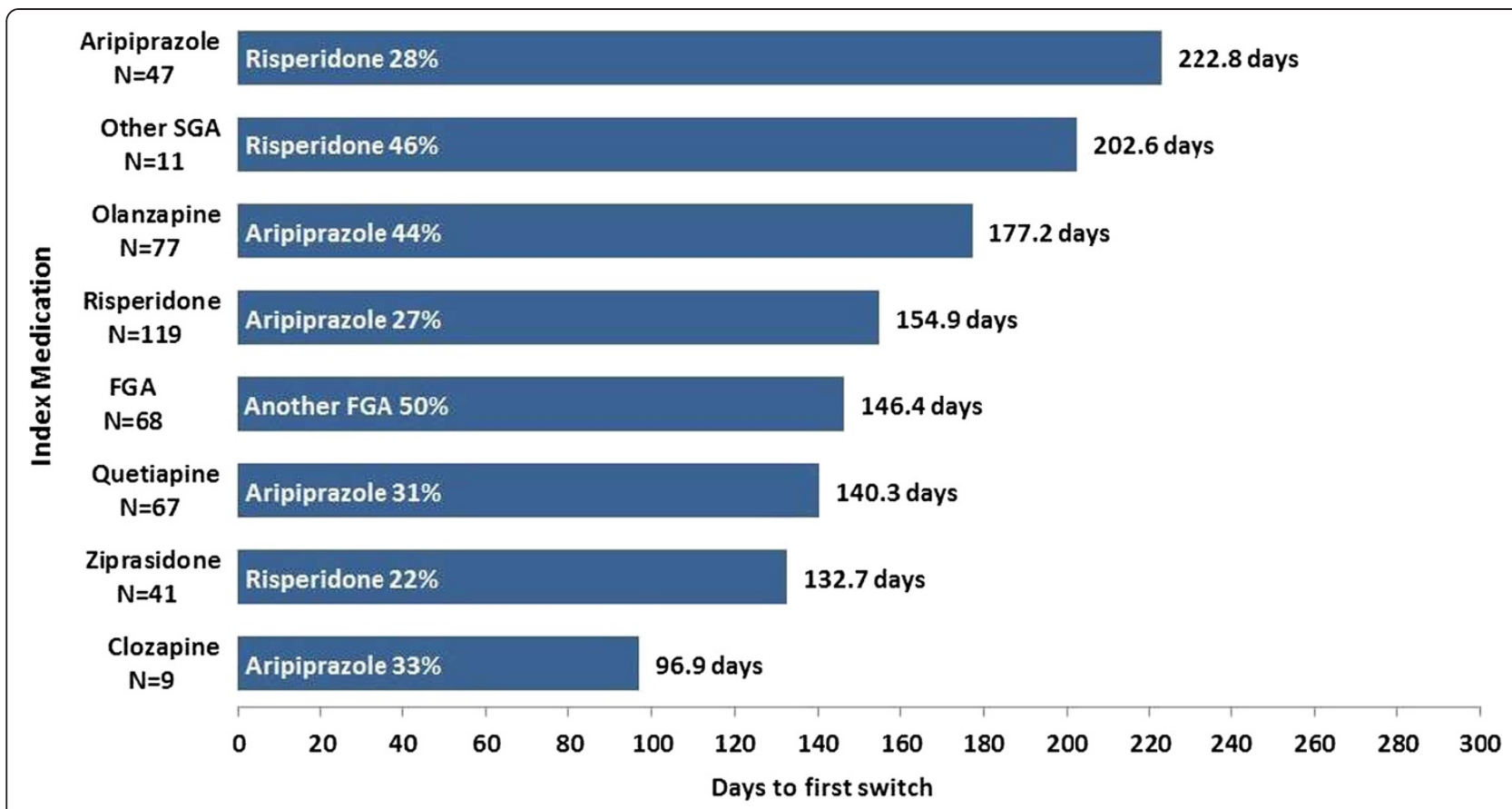

Figure 2 Days to first switch by index medication by medication of most frequent switch among 439 monotherapy patients who switched antipsychotic therapy during 12-month follow-up. FGA = first-generation antipsychotic; SGA = second-generation antipsychotic.

study. Physicians may perceive that use of two SGAs is safer than switching a patient to an SGA, then to clozapine, but these attitudes may be changing with the growing body of evidence that SGAs carry their own serious adverse effects on physical health [34-36]. The use of concomitant psychiatric medications was not only high but also higher among patients in the polypharmacy cohort than the monotherapy cohort. The high use of benzodiazepines is of concern given the recent findings of morbidity and mortality links to benzodiazepine use and polypharmacy use among patients with schizophrenia [10].

Table 6 Antipsychotic switching among patients receiving polypharmacy who discontinued (90 day gap in therapy) $\geq 1$ index antipsychotics during one year follow-up

\begin{tabular}{ll}
\hline & $\mathbf{n}(\%)$ \\
\hline $\begin{array}{l}\text { Patients receiving polypharmacy }{ }^{a} \text { who discontinued } \geq 1 \\
\text { index medications }\end{array}$ & $745(77.0)$ \\
Antipsychotic medication status after discontinuation & \\
$\quad$ Monotherapy with 1 of the index medications & $157(21.1)$ \\
$\quad$ Monotherapy with switch to a new antipsychotic & $134(18.0)$ \\
$\quad$ New polypharmacy regimen including 1 of the index & $66(8.9)$ \\
medications & $62(8.3)$ \\
New polypharmacy regimen with all new antipsychotics & $326(43.8)$ \\
Remained on no antipsychotics & \\
\hline $\mathrm{a}=968$. &
\end{tabular}

The discontinuation rate of $77 \%$ among patients in the polypharmacy cohort is high, but consistent with prior research [34]. The shorter duration of therapy in the polypharmacy cohort may have been related to concerns by physicians over the long-term use of two antipsychotics and may have been an intentional strategy. It is difficult to tease apart non-adherence/persistence on the part of patients from prescribing decisions made by physicians in claims. Another limitation of claims analyses is that we are unable to estimate optimum antipsychotic dose. The post-medication status of patients who entered the study on polypharmacy suggests a number of possible circumstances. In keeping with the known challenges of adherence among patients with schizophrenia, combinations of antipsychotics, which require more complex dosing regimens, and the overall higher pill burden, may make adherence among these patients all the more difficult [10]. Furthermore, lack of efficacy and emergence of side effects may also have led treating physicians to abandon the strategy of polypharmacy. Unfortunately, for patients with severe symptoms that do not fully remit with current treatments, few alternatives are yet available.

\section{Conclusions}

In a real-world analysis, $23 \%$ of patients with schizophrenia received treatment with two or more antipsychotic agents simultaneously. Discontinuation rates were higher 
among patients receiving polypharmacy compared with those receiving monotherapy. Patient age and use of polypharmacy were independent predictors of length of therapy over one year of follow-up.

\section{Competing interests}

M. Fisher is an employee of HealthCore, Inc. as was K. Reilly at the time of this study. HealthCore, Inc. received funds from Genentech to conduct this study. M. Fisher and K. Reilly did not receive direct payment. K. Isenberg is an employee of WellPoint, Inc. and received no payment for this study. K. Villa was an employee of Genentech, Inc at the time of this study.

\section{Authors' contributions}

MF was involved in study design, drafting/revising manuscript content, analysis and interpretation of the data. KR was involved in study design, statistical analysis, drafting/revising manuscript content and interpretation of data. KI was involved in study design, interpretation of data and drafting/ revising manuscript content. KV was involved in study design, drafting/ revising manuscript content, analysis and interpretation of data. All authors read and approved the final manuscript.

\section{Acknowledgements}

This analysis was supported by Genentech, Inc.

Editorial support was provided by InVentiv Health and funded by F. Hoffmann La Roche. Journal processing fees were provided by F. Hoffmann La Roche.

\section{Author details}

${ }^{1}$ HealthCore, Inc., 800 Delaware Ave. 5th Floor Wilmington, Delaware 19801-1366, USA. ${ }^{2}$ Wellpoint, St. Louis, Missouri, USA. ${ }^{3}$ Jazz Pharmaceuticals, Inc., 3180 Porter Drive, Palo Alto, CA 94304, USA.

Received: 5 March 2014 Accepted: 18 November 2014

Published online: 30 November 2014

\section{References}

1. Erhart SM, Marder SR, Carpenter WT: Treatment of schizophrenia negative symptoms: future prospects. Schizophr Bull 2006, 32:234-237.

2. Miyamoto S, Miyake N, Jarsog LF, Fleischhacker WW, Lieberman JA: Pharmacological treatment of schizophrenia: a critical review of the pharmacology and clinical effects of current and future therapeutic agents. Mol Psych 2002, 17:1206-1227.

3. Ascher-Svanum H, Nyhuis AW, Faries DE, Kinon BJ, Baker RW, Shekhar A: Clinical, functional, and economic ramifications of early nonresponse to antipsychotics in the naturalistic treatment of schizophrenia. Schizophr Bull 2008, 34:1163-1171.

4. Lecrubier Y, Perry R, Milligan G, Leeuwenkamp O, Morlock R: Physician observations and perceptions of positive and negative symptoms of schizophrenia: a multinational, cross-sectional survey. Eur Psych 2007, 22:371-379.

5. Novick D, Haro JM, Hong J, Brugnoli R, Lepine JP, Bertsch J, Karagianis J, Dossenbach M, Alvarez E: Regional differences in treatment response and three year course of schizophrenia across the world. J Psychiatr Res 2012, 46:856-864.

6. Anil Yağcioğlu AE, Kivircik Akdede BB, Turqut TI, Tümüklü M, Yazici MK Alptekin K, Ertuğrul A, Jayathilake K, Göğüş A, Tunca Z, Meltzer HY: A double-blind controlled study of adjunctive treatment with risperidone in schizophrenic patients partially responsive to clozapine: efficacy and safety. J Clin Psych 2005, 66:63-72.

7. Centorrino F, Goren JL, Hennen J, Salvatore P, Kelleher JP, Baldessarini RJ: Multiple versus single antipsychotic agents for hospitalized psychiatric patients: case-control study of risks versus benefits. Am J Psych 2004, 161:700-706.

8. Honer WG, Thornton AE, Chen EYH, Chan ECK, Wong JOY, Bergmann A, Falkai P, Pomarol-Clotet E, McKenna PJ, Stip E, Williams R, MacEwan GW, Wasan K, Procychyn R: Clozapine alone versus clozapine and risperidone with refractory schizophrenia. N Engl J Med 2006, 354:472482.

9. Leucht S, Kissling W, McGrath J: Lithium for schizophrenia. Cochrane Database Syst Rev 2007, 18:CD003834.
10. Fleischhacker WW, Uchida H: Critical review of antipsychotic polypharmacy in the treatment of schizophrenia. Int $J$ Neuropsychopharmacol 2007, 17:1-11.

11. Gilmer TP, Dolder CR, Folsom DP, Mastin W, Jeste DV: Antipsychotic polypharmacy trends among Medi-Cal beneficiaries with schizophrenia in San Diego County, 1999-2004. Psychiatry Serv 2007, 58:1007-1010.

12. Goff DC, Dixon L: Antipsychotic polypharmacy: are two ever better than one? Am J Psych 2011, 168:667-669.

13. Ito H, Koyama A, Higuchi T: Polypharmacy and excessive dosing: psychiatrists' perceptions of antipsychotic drug prescription. $\mathrm{Br} J$ Psych 2005, 187:243-247.

14. Koen L, Magni P, Niehaus DJH, Le Roux A: Antipsychotic prescription patterns in Xhosa patients with schizophrenia or schizoaffective disorder. Afr J Psych 2008, 11:287-290.

15. Paton C, Lelliott P, Harrington M, Okocha C, Sensky T, Duffett R: Patterns of antipsychotic and anticholinergic prescribing for hospital inpatients. J Psychopharmacol 2003, 17:223-229.

16. Procyshyn RM, Honer WG, Wu TKY, Ko RWY, Mclsaac SA, Young AH, Johnson JL, Barr AM: Persistent antipsychotic polypharmacy and excessive dosing in the community psychiatric treatment setting: a review of medication profiles in 435 Canadian outpatients. J Clin Psych 2010, 71:566-573.

17. Santone G, Bellantuono C, Ricci P, Picardi A, Preti A, De Girolamo G: Patient characteristics and process factors associated with antipsychotic polypharmacy in a nationwide sample of psychiatric inpatients in Italy. Pharmacoepidemiol Drug Saf 2011, 20:441449.

18. Stahl SM, Grady MM: High-cost of second-generation antipsychotics under California's medicaid program. Psychiatr Serv 2006, 57:127-129.

19. Tsutsumi C, Uchida H, Suzuki T, Watanabe K, Takeuchi H, Nakajima S, Kimura Y, Tsutsumi Y, Ishii K, Imasaka Y, Kapur S: The evolution of antipsychotic switch and polypharmacy in natural practice - a longitudinal analysis. Schizophr Res 2011, 130:40-46.

20. Xiang YT, Weng YZ, Leung CM, Tang WK, Ungvari GS: Clinical and social determinants of antipsychotic polypharmacy for Chinese patients with schizophrenia. Pharmacopsych 2007, 40:47-52.

21. Faries D, Ascher-Svanum H, Zhu B, Correll C, Kane J: Antipsychotic monotherapy and polypharmacy in the naturalistic treatment of schizophrenia with atypical antipsychotics. BMC Psych 2005, 5:26.

22. Gallego JA, Bonetto J, Zhang J, Kane JM, Correll CU: Prevalence and correlates of antipsychotic polypharmacy: a systematic review and meta-regression of global and regional trends from the 1970 s to 2009 . Schizophr Res 2012, 138:18-28.

23. Ganguly R, Kotzan JA, Miller S, Kennedy K, Martin BC: Prevalence, trends, and factors associated with antipsychotic polypharmacy among Medicaid-eligible schiozophrenia patients, 1998-2000. J Clin Psych 2004, 65:1377-1388

24. Cipriani A, Boso M, Barbui C: Clozapine combined with different antipsychotic drugs for treatment resistant schizophrenia. Cochrane Database Syst Rev 2009, (3): CD006324

25. Josiassen RC, Joseph A, Kohegyi E, Stokes S, Dadvand M, Paing WW, Shaughnessy RA: Clozapine augmented with risperidone in the treatment of schizophrenia: a randomized, double-blind, placebo-controlled trial. Am J Psych 2005, 162:130-136.

26. Shiloh R, Zemishlany Z, Aizenberg D, Radwan M, Schwartz B, Dorfman-Etrog P, Modai I, Khaikin M, Weizman A: Sulpiride augmentation in people with schizophrenia partially responsive to clozapine. A double-blind, placebo-controlled study. Br J Psych 1997, 171:569-573.

27. Zink M, Englisch S, Meyer-Lindenberg A: Polypharmacy in schizophrenia. Curr Opin Psych 2010, 23:103-111.

28. Baandrup L, Sørensen J, Lublin H, Nordentoft M, Glenthoj B: Association of antipsychotic polypharmacy with health service cost: a register-based cost analysis. Eur J Health Econ 2010, 13:355-363.

29. Gallego JA, Nielsen J, De Hert M, Kane JM, Correll CU: Safety and tolerability of antipsychotic polypharmacy. Expert Opin Drug Saf 2012. 11:527-542.

30. American Psychiatric Association: Practice Guideline for the Treatment of Patients With Schizophrenia, second ed. Arlington, VA, USA: American Psychiatric Association; 2004.

31. Deyo RA, Cherkin DC, Ciol MA: Adapting a clinical comorbidity index for use with ICD-9-CM administrative databases. J Clin Epidemiol 1992, 45:613-619. 
32. Bauer MS, Mitchner $L$ : What is a "mood stabilizer?" An evidence-based response. Am J Psych 2004, 161:3-18.

33. Leucht S, Heres S, Kissling W, Davis JM: Evidence-based pharmacotherapy of schizophrenia. Int I Neuropsychopharmacol 2011, 14:269-284.

34. Lieberman JA, Stroup TS, McEvoy JP, Swartz MS, Rosenheck RA, Perkins DO, Keefe RS, Davis SM, Davis CE, Lebowitz BD, Severe J, Hsiao JK: Effectiveness of antipsychotic drugs in patients with chronic schizophrenia. N Engl J Med 2005, 353:12091223.

35. Lieberman JA, Stroup TS: The NIMH-CATIE schizophrenia study: what did we learn? Am J Psych 2011, 168:770-775.

36. Üçok A, Gaebel W: Side effects of atypical antipsychotics: a brief overview. World J Psych 2008, 7:58-62.

doi:10.1186/s12888-014-0341-5

Cite this article as: Fisher et al: Antipsychotic patterns of use in patients with schizophrenia: polypharmacy versus monotherapy. BMC Psychiatry 2014 14:341.

\section{Submit your next manuscript to BioMed Central and take full advantage of:}

- Convenient online submission

- Thorough peer review

- No space constraints or color figure charges

- Immediate publication on acceptance

- Inclusion in PubMed, CAS, Scopus and Google Scholar

- Research which is freely available for redistribution 